\title{
Plausibility and probability in scenario planning
}

\author{
Ramirez, Rafael ; Selin, Cynthia Lea
}

Published in:

Foresight

Link to article, DOI:

10.1108/FS-08-2012-0061

Publication date:

2014

Link back to DTU Orbit

Citation (APA):

Ramirez, R., \& Selin, C. L. (2014). Plausibility and probability in scenario planning. Foresight, 16(1), 54-74. https://doi.org/10.1108/FS-08-2012-0061

\section{General rights}

Copyright and moral rights for the publications made accessible in the public portal are retained by the authors and/or other copyright owners and it is a condition of accessing publications that users recognise and abide by the legal requirements associated with these rights.

- Users may download and print one copy of any publication from the public portal for the purpose of private study or research.

- You may not further distribute the material or use it for any profit-making activity or commercial gain

- You may freely distribute the URL identifying the publication in the public portal

If you believe that this document breaches copyright please contact us providing details, and we will remove access to the work immediately and investigate your claim. 


\title{
PLAUSIBILITY AND PROBABILITY IN SCENARIO PLANNING
}

\author{
Rafael Ramirez (Oxford University) \& Cynthia Selin (Arizona State University)
}

Foresight

Accepted for publication in April 2013.

\section{Structured Abstract:}

For decades scenario planners have debated the relative merits of using plausibility and probability in their methodology. Preference for the one or the other distinguishes not only techniques and tools, but comprises whole schools of thought, determines criteria for effectiveness, and suggests not only epistemological but also ontological differences. In this article we critically examine both concepts: their etymology and history, their cultural connotations, and their relationships. We find that the relationship between both concepts is more complex and more nuanced, that over time it has varied, and that much more clarity is called for when invoking each both on its own merits and in counter-distinction to the other. The paper makes two contributions: it demystifies some of the distinctions that influential authors have called upon to classify scenario approaches, laying bare unfounded biases and unhelpful and even artificial and self-serving differences. In so doing it provides practitioners a more nuanced appreciation of the merits of plausibility and probability, providing a more rigorous and scholarly view, so that they can be more effectively referred to when making choices of method and approach.

Keywords: scenario planning, plausibility, probability, methodological choice, scenario planning 'schools'

Article Classification: Theoretical

\section{INTRODUCTION}

In this paper we unpack and examine the oft-repeated claim by many in the scenario planning community that a key performance indicator of scenarios effectiveness is plausibility. We explore what lies behind this claim and how it works in practice, as well as theoretically. The paper contributes to a more rigorous theoretical understanding of plausibility, its relations with and differences with probability, and how they have been and still are related. We suggest that the links between them have been more complex than has generally been accepted, and clarify how the distinction can be more helpfully drawn to enhance the effectiveness of scenario work.

The paper is organised as follows. First, we contrast retrospective and prospective sense-making and sensegiving. Then we analyze how the etymological history of the terms 'probability' and 'plausibility' has confused much of the ongoing debate, and claims and counter-claims on both. In an appendix we illustrate this confusion by analyzing Millett's (2009) treatment of probability in scenario planning. This is followed by an exploration of three cultural dynamics present throughout the etymological history. This exploration dissects a thirst for wishing to settle, one way or another, on one's preference for plausibility or probability and the certainties they afford: an urge to use either to diminish the anxiety that an undecided and undefined question - a mess (Ackoff, 1981) - causes. This dissection picks apart scenario planning processes in finer 
resolution, to show that different authors summon plausibility and probability not indiscriminately, but to serve given purposes at different stages in the process. While preference for either plausibility or probability matters in any one stage, honouring a deeper dynamic which attends to the discomfort and avoiding probability or plausibility too early helps to deepen learning with scenarios (de Geus, 1988; Chermack and van der Merwe, 2003) and generate productive insight. We then relocate the contradistinctions Millett (2009) made within a broader conceptual space that captures the central intents of scenario planning, whether they are so see anew or gently re-perceive (Wack, 1984), redirect attention to what has been peripheral or in the background (Haeckel, 2004; Ramirez et. al. forthcoming), imagine what has been ignored (Rosenthal, 1966), evoke insight (van der Heijden, 1996), correct bias (Wright and Goodwin, 2009), surface assumptions (Ramírez et al., 2008) , test or develop new options (Wilson, 2000), or build new social capital fast (Lang, 2012). We conclude by proposing that the result of this broader reframing of the plausibility-probability debate can render scenario work more robust and more relevant to current challenges to avoid considering probability and plausibility as a zero sum game.

The paper builds on work in prior workshops held at the University of Oxford (Oxford Futures Forum, 2008) and at Arizona State University (CSPO, 2009) ${ }^{1}$. The paper makes two major contributions in unravelling the theoretical dilemmas posed by the compromised use of plausibility and probability. First, it critically examines what appears to be a widely accepted (and often un-reflexive) distinction between 'plausibility' and 'probability' in scenario work. These are considered to be fundamental either/or criteria undergirding important methodological choices that influential scholars have gone as far as considering them to define different schools in scenario planning (Bradfield et al., 2005). As the attention on scenario planning continues to grow (Varum \& Melo 2010), understanding how plausibility and probability operate and relate to each other clarifies where these distinctions are valid, and where each can and cannot legitimately be used. Sorting out this distinction offers a secondary and supporting contribution related to the qualities of effective scenario work - notably in making expectations of what scenarios can do easier to define ex-ante and to be met expost. This second contribution shows why probability cannot be used as criterion for scenario work, or as a basis to select a given scenario as 'most likely' (here we disagree with Millet), but that it can be used within scenario work in ways that are developmental and not regressive (Freud, 1920).

We define scenarios as a small set of stories of future contextual conditions linked with the present, made for someone and fulfilling an explicit purpose. This differs from Glenn's (2009) seminal definition in its triple focus on the context, users and purpose.

\section{SENSE-MAKING: RETROSPECTIVE AND PROSPECTIVE}

Prospective sense-making is a seldom-explored element of organizing (except in leadership research) although it is increasingly important as business, political, financial and social systems become more complex, interrelated, uncertain and turbulent. The past is a reasonable guide when growth is stable and past and present trends can be extrapolated reliably to account for emergence. However when change is novel, unexpected, 
unforeseen, unique, and / or radical, perhaps involving also manifold unintended consequences; the future and the uncertainty it holds means organizations can no longer rely on past or unfolding trends. Making sense of uncertain futures becomes a key survival skill within organizational life in turbulent times (Ramírez et. al, 2010).

For Weick, sensemaking in organizational theory describes how meaning is constructed from experience. He was explicit in his retrospective focus: "The basic idea of sensemaking is that reality is an ongoing accomplishment that emerges from efforts to create order and make retrospective sense of what occurs" (Weick, 1993: 635). Critical reviews drew attention to the possibility of prospective sensemaking: "prospective sense making is aimed at creating meaningful opportunities for the future. In a loose sense, it is an attempt to structure the future by imagining some desirable (albeit ill-defined) state. It is a means of propelling ourselves forward-one that we conceptualize in the present but realize in the future." (Gioia and Mehra, 1996:1229). Choo and Bontis called this "sense-giving", which "articulates a collective vision for the organization" (2002:81) and attends to the importance of interpretation in the prospective-it is not about locating or finding sense, but offering sense to fill imperfect knowledge and lack of understanding gaps to reduce anxiety.

Scenario planning seeks to rigorously surface and analyze assumptions about the future context to develop strategies, and (2002:81) the plausibility camp holds is most relevant when forecasting from past data sets whose distribution and the trends they suggest are unreliable (van der Heijden, 1996; Ramirez et al, 2010). Wright (2005) first examined scenarios as a means of prospective sensemaking, warning this disrupts rational decision makers (Davidson, 1982) in their espoused use of concrete data and facts.

Scenario planning can serve as a "time reckoning system" (Selin, 2006:196) where sense is made forward and backward, drawing in both retrospective and prospective sensemaking iteratively. It raises fundamental questions about the limits of knowledge, the constraints of ignorance, the power of imagination, representation and communication forms, how uncertainty is accounted for and addressed, and what timescapes (Adam, 1998) can be identified. In scenario planning, imagination and intuition are combined with rigorous analysis. It also attends to experience, professional and cultural biases, representational heuristics, and rationality limitations. Within the practice of scenario planning, such issues have often been bounded in debates over plausibility and probability.

Wilkinson suggested that "Attempts to clarify the general methodological confusion about scenario practicespractices which encompass probable, plausible or possible futures - is already evident" (2009:110). Yet, despite multiple clarification attempts, methodological confusion remains rampant, and in our view extends to the epistemological disagreements of what is subsumed to what. For example, Godet suggested that "The uncertainty of the future can be appraised through the number of possible scenarios within the field of probables" $(2000$, p7), thus situating the possible within the probable. Yet for others, the position of the probable is within the possible, inversing the relationship: 
"The future is an ever widening cone of possibility extended forward from the present moment. There is no future waiting to happen. There are probabilities which are related to current moments for which we cannot have total information but the further ahead we project, the more of these are likely to disrupt dramatically any extension of our own current moment and our extensions of the past" (McMaster, 1996:150, emphasis in the original).

That the topology of the future is assumed to be conical, typically depicted sideways, starting from a single point today and moving to a broader set of equi-possible future states (see UK Government Office for Science, 2009, p. 14; Schoemaker et. al, 2013, p.818)) , is puzzling. How can this assumption hold? Why has that specific topological representation taken up credence? To our knowledge no empirical evidence supporting this assumption has been developed. For all we know in some situations the future is tetrahedrical and in others it takes the form of a teddy bear.

In any case, work that contributes to unravelling the confusions Wilkinson alludes to, and particularly unpacking the unsatisfactory and unproductive distinctions between plausibility and probability, is the central task of this paper. In doing so, we begin to articulate some of the knowledge quality issues that we hope will make prospective sense-making more effective.

There are several possible entry points to unravel the contemporary debates about plausibility and probability in scenario planning. We begin by examining the etymology to better ascertain how the history of each of these terms affects their descriptions and relevance. This suggests that definitional issues undergrid cultural preferences for given epistemological preferences.

\section{THE CHEQUERED PAST: THE ETYMOLOGICAL HISTORY OF THE PLAUSIBILITY-PROBABILITY DISTINCTION}

The etymology of plausibility and probability in English has three distinct periods - a confused one up to and including the $16^{\text {th }}$ century; a transition period in the $17^{\text {th }}$ century wherein probability becomes part of the then unfolding and distinct field of science, and a clearer distinction period as of the $18^{\text {th }}$ century. In the first period (see figure one), both terms are confused as both derive from classical Latin, which largely confused them. Probability first appeared in English in 1387 and plausibility over 150 years later, in 1541. In the $16^{\text {th }}$ century probability denoted 'appearing' truthful and plausibility 'seeming reasonable or probable'. Both were perception, not fact. Yet already then probability is associated with 'likelihood' whereas the possibility of abusing plausibility as 'false appearance' - which as we show below developed over the centuries into a consummate art - had already begun. Plausibility from its very beginning lent itself to what today is called 'spin', as it is etymologically linked with 'applause', expressing publicly available forms of approbation as early as 1542. Plausibility is also more attached to how a person is perceived than probability ever was. 
The 17th century saw a transition for each word and for their relationship. As is shown in figure two, the deceptive aspects of what plausibility can entail became further entrenched both for individuals and doctrines; whereas probability started to become somewhat scientific - though not yet mathematical - and related to observational rigour. It was at this time, and most notably thanks to Locke (1690), that probability was established as inference when insufficient experiential evidence was available to discover what inquisitive men sought through strong judgement. In the $17^{\text {th }}$ century probability thus became noble, whereas the credentials of plausibility remained suspect.

- Figure two about here -

As per figure three, as of the $18^{\text {th }}$ century, each term became more distinct. Probability denoted something served by, and even defined by, mathematical calculus. Probability most importantly became a central aspect of statistics, which itself quickly was very widely applied from its agricultural origins, through to ammunitions testing and thence to all matters of productive activity and policy. Plausibility in this third period referred to a consideration of what is 'probable' as that which is 'seemingly reasonable', and continued in its original sense of providing 'the appearance of believability and credibility'. It is the not innocuous 'appearance of' element in the definition of plausibility that lends it to be (ab-)used for specious spin, culminating in the practice developed by US administrations as of 1978 of institutionalised State lying which came to be known in the Oxford English Dictionary as 'plausible deniability' (OED, 2012). On the positive side, plausibility is considered a feature of credible cause-effect relations.

- $\quad$ Figure three about here -

In short, the two words have been confused with each other for centuries, and even although they became much more distinct in the last 300 years, today plausibility often still deploys probability to define itself. Plausibility, and its connections with the pliable notion of what can be applauded, quite quickly became something which one could fashion to ends of appearing truthful when actual truth might be wanting. On the other hand, probability - and the likelihood it sought to express - first started to become 'scientific' when it could start to be taken as an approximation of fact when evidence was lacking. Probability came to be considered much more scientific when it was possible to express this in 'mathematical' - and thus numerical terms. In so doing, the numbers that probability can deploy in its action have come to lend it a 'noblesse' that plausibility never obtained. For Bayesians, who have become highly influential, probability is the degree of belief that is objective and rational, not simply the relative frequency of occurrence of an outcome in given conditions on which Bayesians found these beliefs. Probability has thus come to measure belief, whereas plausibility simply proposes it, and in the eyes of objective Bayesians, lends itself to subjective manipulation. As a study where numbers were deployed in a complex decision-making situation, with many stakeholders and objectives in co-existence, concluded: "the power of numbers lies in their ability to fill the strategic void created by pluralism" (Denis et al., 2006:349). For those advocating plausibility, however, probability is nonsensical and irrelevant if the future possible situation faced is a unique one: they argue that neither the 
relevant data set nor distribution of it that probability can marshal is available in such circumstances, and calling upon it in such circumstances is fraudulent.

That the exploration of the relative merits and roles of probability and plausibility in organizational studies continues to this day, and has not been resolved, we think is due to the historical complex relations between both. Thus, while Meckler and Baillie proposed that the usefulness provided by scientific method was precisely the move from plausibility (2003:276), Bosch argued that, in practice, plausibility is a better assessment of truth within a constructivist epistemology - for him a theory can be accepted as plausible when it is "in accordance with (practical) empirical findings; subjective/inter-subjective ideas, thoughts, and feelings; and the opinions of and cultural categories used by others" (2010:387). In the appendix we review how these confusions apply to Millet's work and we suggest in it that he - like many of us working with the English language - is a prisoner of the confusions built into the language ${ }^{2}$.

\section{THREE CULTURES OF SCENARIO PLANNING AND THEIR MODELS OF PLAUSIBILITY AND PROBABILITY}

Here we propose that the etymological confusions reviewed above are apparent in three distinctive but related culture clashes in scenario work. Each clash manifests preferences for plausibility or probability in its own way. First we have the qualitative vs. quantitative divide. While often related to disciplinary orientation, a tendency to privilege an either quantitative or qualitative approach is often related to institutional context. A second clash arises with one camp epistemologically wanting to approximate prediction, while the other believes scenarios are only of help in intrinsically uncertain situations that are unforecastable. The final clash concerns the roles of creativity and codified knowledge in alternative futures, rendering scenario planning as entailing either 'art' or 'science'.

The etymological confusions manifested in cultural divides makes each side value the relative truth merits of numbers and narratives incompatibly. One worldview privileges a deductive, positivist and reductive approach that approximates reality truth claims through exclusion - as in laboratories and controlled experiments - and simplification - as in models with assumptions that can ideally be completely captured in formulae, statistics, and regressions. This is a scientific gaze and aims to be predictive. But this approach relies on facts, which are all in the past: even if positivist model assumptions take projections 'for a fact' they are not yet, actually, factual. The approach is also of necessity fragmented: "science has emphasized thinking about "origins" rather than "emergence", about "feedback" rather than "feed-forward", about "learning from the past" rather than "anticipating the future". The inevitable corollary of that tendency is the fragmentation of our world view that we now see as one of the main handicaps in our attempts to understand the full complexity of the processes going on around us..." (van der Leeuw et al., 2011: 4). With fragmentation, the privileging of one perspective implies back-grounding others. It has a focus on one model held to have predictive applications; it frames attention and discounts other means to understand and interpret change, which from the point of view of "hard' (quantifiable) science is taken as "soft" (non-quantified) and "less serious" regardless of how effective they can be - e.g. psychoanalysis. 
Scenario planning has not been immune to this clash of cultures. Wilkinson playfully referred to this split as consisting, on the one hand, of "Homo-Deductivist', the formal-expertise focussed, evidence led, computermodelling based, often probabilistic scenarios folks; and on the other side is 'Homo-Constructivist', the qualitative - evidence led, intuitive causal logics, storytelling, plausible or possible but certainly not probable futures, scenario folks" (2009: 110-111). The two species hold incompatible conceptions of knowledge and uncertainty, as depicted graphically in the bifurcation slide she proposed, which we have adapted in figure four.

- Figure four about here -

Wilkinson's distinction contrasts two incompatible assumptions and objectives in dealing with uncertainty: (1) for those she labelled futurologists, uncertainty is seen as an enemy to be attacked, reduced, and ideally vanquished; perhaps mostly addressed through collecting all that one can know through objective means to reduce uncertainty as much as possible. The products this effort delivers are considered 'objective' and thus true for anyone - like weather predictions. (2) Those she considered to be involved in futurizing accept irreducible limitations to knowing and instead appreciate and engage intrinsic uncertainty. Here the inquiry is for someone and with a purpose, not for anyone, and effectiveness criteria cannot include the form prediction understood as forecasting. The authors are in this camp.

Futurologists thus seek to 'predict the future' whilst the other camp works to 'appreciate plausible futures'. The strong Western scientific quest for more accurate prediction has been strengthened by enhanced data collection and processing capabilities spawned by the information technology revolution. Critics of prediction highlight empirical evidence of prediction failures, incommensurability of human values, and posit the inherent unknowability of times yet to come which are not represented by present or past facts and their probability distributions (Sarewitz et al., 2000). While futurizers may use methods used by futurologists, their epistemological stance is radically different in its insistence on unpredictability, multiple futures, discontinuous change, transformative viewpoints that bring about new units of analysis and categories (e.g. "hippies", "yuppies", "tablets", "the Arab Spring") which were not available ex-ante; and empirical evidence of selforganised or autopoetic - and unpredictable - emergence (Maturana and Varela, 1980).

These two incompatible cultures on how to most effectively engage uncertain future contexts are often confused with two other cultures: one which favours the quantitative and another which favours the qualitative. It isn't mere methodological differences which distinguishes them, but deeper perspectives on the very nature of what is to be done and how to assess effectiveness. While many scenario planners acknowledge that there is room for both approaches; the salience of each; their mix, limits, and advantages; and -most important - which frames the other, define this debate. While both approaches can be used to predict, and 
both can be used to appreciate plausible possibilities, the use of quantitative methods is culturally more tied to probability and the use of qualitative tools more linked to plausibility. In the scenario planning community the clash is most centrally manifested in the difference between - on the one hand - what Bradfield et al. (2005) called the 'intuitive logics' school - preferring plausibility; and - on the other hand - the Battelle (Millet, 2009) and Godet (2000) approaches, which place factors in cross-impact tables and attribute probabilities to the scenarios these analyses yield. According to Postma and Libel (2005) and Ringland (1998), the 'intuitive logics' school of scenarios is the most widely used. A distinctive characteristic of the intuitive school is that it explicitly considers probability to be irrelevant in scenario work and uses plausibility precisely because it considers scenarios are used in situations where probability cannot operate and forecasting is impossible.

In Millet's (2009) thoughtful examination on why probabilities should be used with scenarios, he used a framework he developed six years earlier (Millett, 2003) to survey a history of scenario planning centred on distinguishing between both approaches. The approach that uses probability in conjunction with scenario work includes Millett's own professional experience with Battelle - but he ignores another version of that school developed in France that has been taken up in 'prospective' studies by the European Commission (Godet, 2000). Probability works as follows:

"the Battelle approach to generating scenarios used as many as 24 descriptors (not just the primary two employed to create the structure, or two-by-two matrix, of intuitive scenarios). A descriptor was a trend, issue, or factor relevant to the topic question. Each descriptor had two to four alternative outcomes, or states, by a target year, and each state was assigned an a priori probability of occurrence. A matrix arrayed all descriptors and their states against all other descriptors and their states. Expert judgment was also used to assign cross-impact values to the cells of the matrix, and the algorithm then used the cross-impact values to adjust the a priori probabilities up to 1.0 (occur) or down to $O$ (not occur). The software also organized the scenario clusters according to their frequency of occurring, so that there were resulting scenarios and most likely outcomes presented as a posteriori probabilities". Millett (2009:64, emphases added).

A slightly modified version of Millett's 2003 historical review of scenario planning, distinguishing both schools and outlining their links graphically is reproduced as figure five ${ }^{3}$.

- $\quad$ figure five about here -

The intuitive logics school proposes that scenarios seeking to (re-)establish plausibility better explore possibility than scenarios seeking or using probability, which is impossible in Knightian uncertainty (Knight, 1921; Ramirez and Ravetz, 2011). Yet deriving plausibility from intuition is problematic: Whereas Klein celebrated the 'power' of intuition (2002; 2004), and Gershon (1999) explored the important function of gut feelings in its physiology, Myers (2002) examined how, if left unchecked, intuition all too often leads to misfortune. Kahneman and Klein's (2009) review of what is known about intuition strongly suggests that it operates only in more stable, certain, and predictable environments than those in which scenario planning is relevant (Ramírez et al., 2010). Loewenstein et al. (2001) show that affective and emotive experiences 
expressed as 'gut reactions' are neural and in this sense are mindful, cognitive contributors to gauge potential futures. Through that perspective, intuition can be viewed as an amalgamation of tacit and explicit knowledge that taps ignorance and combines it with creativity and design (Hatchuel et al., 2004) in a sort of reflexive experience that lets go of a-priori categories (Ramírez and Ravetz, 2011). Here attention to other sensory perceptions can play a significant role in understanding plausible and challenging possible futures. Plausibility (whether derived from intuition or gut feelings or not) can be mapped with systems diagram to articulate explicitly how the plausibility works causally (van der Heijden, 1996; Vennix, 1996). Wack (1984) suggested that it is on this basis of comparing plausible imagination and causal logic through analysis that sense is made and the bases for decisions improved. Proponents of this approach underline that plausibility invites further inquiry whereas probability closes it down.

Above we noted that for plausibility-centred scenario planners, probability is meaningless in situations when one cannot consider data distributions from the past to be relevant for uncertain futures (Ramírez and Ravetz, 2011). Furthermore, Starbuck and Mezias argue that even if such data of the future was somehow available, it does not appear to be used in practice. Their review of two decades of research on managerial perception concluded that "on average, managers' perceptions of their environments' stabilities do not correlate with 'objective' measures of those stabilities" (2003:5). While Starbuck and Mezias “assumed people need to perceive problems accurately in order to solve them, (they) eventually realized that most problem solving, possibly all problem solving, does not depend on accurate knowledge of current situations" (2003:15). Yet those in the camp that prefers to use probability with scenarios (1) consider that the probable contains the possible (Godet, 2000); and/or have found through experience (2) that thinking of scenarios as equally plausible might perhaps be desirable in principle but is impossible in practice (Millett, 2009). Millett also argues (3) that having to directly justify one's thinking in terms of probabilities forces finer articulation of what might otherwise be bucketed as intuition.

Despite the problems of separating plausibility from probability we examined earlier, the two best-selling books in the so-called intuitive school of scenario work, Schwartz's 'The Art of the Long View' (1991; revised, 1996) and van der Heijden's 'Scenarios: The Art of Strategic Conversation' (1996; revised, 2005) do make that separation, and move the qualitative/quantitative distinction to reflect two other cultures - the arts and the sciences. Both books consider scenario work an art, not a science - which we take as their implying that plausibility is more pertinent than probability. Schwartz considers scenarios as memories of the future (p. 32), stories (p. 37), or myths (p. 39) to which assigning probabilities should be avoided (p. 247). For van der Heijden scenarios also are plausible 'perception devices' that are distinct from 'the conceptual activity of forecasting' associated with probability (p. 29). Bernard de Jouvenel (1967) too considered engaging with the future to be an art. Another influential scenario practice, that of the consulting firm McKinsey, appears to also consider that "In a highly uncertain environment, the advantages of scenario planning are clear: since no one base case can be regarded as probable, it's necessary to develop plans on the assumption that several different futures are possible" (Dye et. al, 2009:1). Yet in the same firm, Roxburgh believes that "the scenario that is highest in 
probability should always be identified, and that ought to become the base case" (2009:9), "picking the scenario whose outcome seems most likely" (2009:5). How this can be done in the Knightian uncertainty where scenarios are of particular help remains unclear to us.

\section{USING PLAUSIBILITY AND PROBABILITY IN PRACTICE}

Comparing the relative merits of actually deploying a probability-centred approach to scenarios with those of a plausibility-centred approach within a single scenarios situation is difficult for practical and methodological reasons that go well beyond the definitional issues surveyed in the first section, and the cultural ones surveyed in the second one.

Imagine attempting to conduct an experiment to establish which of the two is better. To do that, the experimental setting would have to take into account the purposes and skill of the intended scenario user(s), which would have to remain constant across both approaches; the skills of the scenario team, which would have to be equal in each approach (even if one team did both approaches, they might be more skilful at the one than the other approach); the timing, and quality of the assessment, which would need to be identical; the comparability of the scenario work's contextual conditions, which would have to remain constant; and the metrics or criteria of what is meant by 'effective' so that the comparison made sense. This type of comparison is what laboratories were created for - they isolate experimental conditions so that they are comparable and replicable. In scenario work, which is customer- or user- centric and contingent on context, obtaining this type of constant and isolated conditions is either impossible or very hard indeed to obtain. To our knowledge no one has attempted to conduct such an experiment, which we find unsurprising.

Given this experimental limitation, to further tease apart methodological confusions and the tensions among scenario planning schools, we here attempt to delineate how in different stages in scenario planning plausibility and probability have been summoned. This comparison is not itself objective; each school has given rise to its own 'method', made up of so many phases or stages or steps, and no single common method that each school would recognize as belonging to both exists. We have thus contrived a minimum list of steps each method might recognise as relevant: (1) setting purpose and expectations with the intended user(s) and understanding how the users might use and value the scenario set; (2) engagement design, (3) investigations, (4) scenario development, (5) implications for action - sometimes including dissemination. We suggest that these steps are not always linear - in many cases we have been involved in iterations occur and one must often revisit earlier decisions. Nor are these steps sequential: often some occur synchronically. Nor are they always as distinct from each other as we present them here: sometimes they overlap. But the distinction helps to see how each step can call upon plausibility and probability. We proceed in the order above.

1) SETTING PURPOSE AND EXPECTATIONS WITH THE INTENDED USER \& UNDERSTANDING HOW THE USERS MIGHT USE AND VALUE THE SCENARIO SET 
Probability focused scenarios claim to offer enhanced views of the likelihood of a given future over alternatives. For the plausibility-focused, that purpose is impossible: for them, if one could establish probability about a given future it would be unnecessary to do scenarios. For the plausibility-focused, scenario planning is about manufacturing challenging, relevant future possible contexts for a user and with an explicit use of the scenarios. This means that the expectations and criteria for success of engaging with scenarios depend entirely on which school one intends to use.

\section{2) ENGAGEMENT DESIGN}

Engagement design sets the bounds of the inquiry and its temporal horizons, and defines the collaborative architecture and roles and relations as well as a calendar. Objectives and effectiveness criteria are translated into milestones, performance indicators, and go/no go 'early closure' options. The amount and type of research and form of investigation (data collection, interviews, discovery journeys, workshops) is specified. Much of what happens in this phase influences whether the scenarios will be qualitative or quantitative, and/or based on probability or plausibility.

\section{3) INVESTIGATIONS}

If the focus is on probability, investigations would gravitate towards identifying what data is on hand, what factual evidence exists of unfolding trends, and what research can reveal about how these different units do and may interact. If the focus is on plausibility investigations would unearth explicit and implicit perceptions of stakeholders, decision biases used in the organization being served by the scenarios (Schoemaker, 1993), what has been talked about within the firm in its Board Meetings or other relevant internal documents, as well as with external stakeholders (van der Heijden, 1996), deep cultural myths held and grounding existing world views (Inayatullah, 2002), areas of discomfort (Ramírez and Ravetz, 2011) and ignorance (Hatchuel et al., 2004). In both cases the investigations seek to understand what is known about the future context in question; what is uncertain; what is predetermined; identifying remarkable views about what might happen that differ from each other; determining ongoing trends which might continue, crash, or bend in the scenario period; scoping out things that do not matter to the users and determining which aspects are most useful to them given the purposes and expectations that have been agreed.

\section{4) SCENARIO DEVELOPMENT}

Probability and plausibility matter a lot in this phase. The probabilistic approach uses cross-impact analyses, deriving probabilities of likely relations, impacts, and outcomes, often based on algorithms. Plausibilityfocused scenarios can be produced inductively, where the scenarios are produced first iteratively and then compared; or in a deductive fashion, where the framework for comparing among them is developed first, then the scenarios. 
Each treats 'relevant information' about the future in its own distinct way. The probabilistic scenarios think of the future as calculable; plausibility considers calculability irrelevant. Above we surveyed the confusion in debates on what exactly is meant by 'probable' and by 'plausible' - regardless of how any one intervention sorts these out, there are costs involved in pursuing each approach. .

\section{5) IMPLICATIONS FOR ACTION / DISSEMINATION}

Scenario use and effectiveness also depends whether plausibility or probability has been central. In our experience - contrary to Millet's assessment referred to above, evoking plausibility invites users to further inquiry, whereas assessing probability tends to close inquiry. Iterative investigation with scenarios (van der Heijden's work with Indian Agriculture, 2008; revised, 2010, is an example) is thus well supported by plausibility-focused scenario work.

Probability-focused scenario work, focuses further work on the 'likelier' scenario, whereas plausibility-focused work pursues all scenarios, which are fabricated to be taken as equally plausible. If each scenario is as plausible as the next, each and every scenario is worthy of attention and it is the scenario set, not the single scenario, and the comparisons among them that yield value. The charge within plausibility-focused planning is to keep the ambiguity of the future alive so it can remain productive (see Fox Keller, 2002, for an example of how ambiguity is productive in inquiry).

If the scenarios are not used exclusively by those that produced them, and/or need to be shared or disseminated, altogether different dynamics around plausibility and probability erupt. When scenario sets leave their site of generation (the scenario workshops, the expert's computers, the core production team, maybe the organization that spawned them) and travel to new locations (e.g. the policy milieu, the strategy process, or a public audience) the plausibility/probability debate is tied to the uptake of scenarios instead of defining how they are produced and /or negotiated. Professional cultures of the users, success criteria, legislative frameworks, norms, power structures, transparency regimes - all such organizational, social, psychological, political and cultural aspects in the user communities play a role on how valid and helpful each of plausibility and probability are considered to be.

\section{PLAUSIBILITY AND PROBABILITY AS SOCIAL DEFENCES AGAINST ANXIETY}

Psychology plays an important role in every aspect of scenario work. Social psychologists have found that ambiguity and uncertainty are uncomfortable and can create anxiety (Heath and Tversky, 1991; Cao et al., 2011). Organizational efforts and even designs attempt to address this anxiety by tailoring work so that only 'small chunks' of stress are involved for every individual worker (Menzies Lyth, 1960). This tendency to keep the 'dis' out of 'distress' (Selye, 1974) and keep the 'stress' productive; to fix onto the flux, to construct order out of chaos, and to stand on firm footing appears linked to a basic human need to reduce ambiguity to productive levels, to obtain sufficient certainty, and to deny excessively stressful evil (Cohen, 2001). Seeking to 
end the exposure to stressful ambiguity through closure is made by pushing for greater plausibility and by enumerating probability. Whether through plausibility or probability, at heart is a desire to alleviate the discomfort and distress that ambiguity and uncertainty entail; and to push for comfort, or at least a level of stress that is generative and helpful - not paralyzing and unsettling.

But ambiguity can also be surprisingly fertile and generative. To keep it so, 'transitional spaces' have been designed and created. In transitional spaces the possibility of inquiry-enabling ambiguity is kept safe, helping people to leave the every-day safety to which they are accustomed, enter new and unfamiliar spaces for a limited time, and then re-enter the every-day space having explored the alternative. Social psychologies have studied why it can be difficult to use the helpful complexities of a transitional space, and have designed ways to make the time and work in the transitional space productive (Amado and Ambrose, 2001). The 'gentle art of re-perceiving' that Pierre Wack called scenario planning, may be far from gentle if the transitional space careful scenario work hones is broken, and instead of gently re-perceiving, shock and awe are what is experienced, with high distress and little or very slow learning.

As Weick noted, when approaching non-routine tasks with densely interconnected networks (as is the case in scenario work) ambiguity can be amplified (2001:44). Fox Keller's analysis of the history of biology over the last part of the 20th century suggests that apparently illogical combinations when used as metaphor in science "become the locus of ambiguity" (2002:158-159), performing the crucial generative roles that make science advance. Here ambiguity, like in good scenario work, is an asset to be cherished, not a liability to be avoided. Similar points have been made about 'boundary objects' in science and technology studies - as words, phrases or artefacts that can hold multiple meanings in productive tension (Star and Griesemer, 1989). Selin (2003) argued scenarios can work as boundary objects, usefully containing tensions, contradictions and diverse value systems to enhance understanding.

We suggest that many of the unhelpful debates, struggles and clashes over plausibility and probability can also be understood as efforts to obscure a fundamental concern of how to best keep discomfort (with what is known, ignored, hoped and feared) productive. How then might comparisons between plausibility and probability be better deployed? This is what we survey in the last section of this paper.

\section{DISCUSSION: SAFEGUARDING PRODUCTIVE AMBIGUITY IN SCENARIO PLANNING}

Resisting the urge to find a falsely certain, infertile, and unproductive steady ground in numerical or other accounting - or in overly plausible outcomes - is a key factor of the effective practice of scenario work. Rethinking plausibility and reframing the plausibility-probability debate offers an entry point for more robust assessments of these problematic issues and more effective potential approaches. If an important benefit of scenarios is what Kahn (1962) called to help 'think the unthinkable', and in so doing to surface implicit 
assumptions, test tacit knowledge, question preconceptions of the impossible and the possible, change views and minds; then staying with ambiguity and uncertainty that is productive, rather than seeking the seductive comfort of early but unproductive resolution is a key purpose of scenario work.

It is therefore important to explicitly and reflectively seek to bypass the infertile distinctions we have surveyed and to see how different aspects emerging from both sides of these divides can help to productively deal with discomfort, disagreement, uncommon knowledge, articulating ignorance and ambiguity to more effectively explore what possibilities the future might hold.

Considering the 'knowledge problems' of the future helps here. The knowledge under consideration subjected to plausibilistic and probabilistic judgments - is ethereal. As the future is temporally distanced and hasn't yet taken place, we cannot grasp it. Human beings have fought the alternative - that everything is up to fate. If it were; free will, choice, strategy and agency would be irrelevant. Humans and institutions do influence how the future is made - but not the broader contexts in which it is made. Entrepreneurs think they actually make a future every day through designs, materials, agendas, choices, movements and policies. Yet Adam and Groves (2007) have described futures-in-the-making as 'future presents' and Emery (1977) suggested that it is "Futures We Are In". Both imply futures are events and impacts underway in the present; yet what the future context holds (including the entrepreneur) may - or not - unfold as the entrepreneur expects.

Some latent futures can be and are observed, such as $\mathrm{CO} 2$ emissions whose impact lies in wait, ageing populations, and crumbling infrastructures crying for repair. Wack called these 'predetermined elements' (1984) whose effects are yet to be fully experienced. While his choice of terms removes agency perhaps too drastically, assessing impacts 'if other things are taken to remain unchanged' with reference projections is of help - as the IPCC scenarios attest (Moss et al. 2010). Nevertheless accounting for possible futures (futures in the making) provides no assurance of certainty or comprehensiveness: the IPCC scenarios did not factor in Chinese or Indian manufacturing growth and were thus overly optimistic.

The core of scenario planning is about seeing anew, noticing differently, finding new units of observation and terms to describe these (Normann, 2001), thus exploring the limits of available knowledge and sparking more effective inquiry. Scenario planning is about becoming more uncomfortable with the world's ignorance and making it more productive (Ramírez and Ravetz, 2011). Scenario building works well when it departs from the comfortable familiarity of established plausibility and/or the settling security of purported probabilities to venture into the discomfort of inquiring into the unknown. Our investigations suggest that assigning probabilities or settling into too much plausibility reduces interest into a lowest common denominator made up of commonly held assumptions, baseline expectations, 'the usual suspect' categories, and simplistic preconceptions and extrapolations. This is unhelpful in addressing uncertainty. 
Wilkinson and Eidinow (2008) suggested that 'problem-focused' scenarios might be more effective than 'actorcentric' scenarios, proposing what they termed 'reflexive interventionist or multi-agent based' scenarios for situations that manifest post-normal science (Funtowicz and Ravetz, 1993) conditions. These are characterized by short decision windows, contested validity of facts, high stakes, and uncertain values. In such situations, specifying probability and maximizing plausibility might not be the most helpful way to assess scenario effectiveness. Instead, we propose that the scenarios which might better help to guide action in post-normal uncertainty are those considered highly implausible and uncomfortable- those outside existing mental models and framings that contest their relevance and validity. Of course, a scenario that is considered totally implausible or improbable would be rejected as irrelevant, but a scenario that seeks to make discomfort and ignorance productive in further inquiry would be of greater help than one that is highly probable or very plausible. This is depicted in figure six, drawing from Tony Hodgson (personal communication, 15 April 2008).

- Figure 6 about here -

So an alternative criterion to establish scenario effectiveness - instead of likely or plausible or probable would be the extent to which it causes productive discomfort. The scholarly treatment of this dates back to Coulson's 1985 Malinowski Award Address:

"It is a common charge that the social sciences, including anthropology, are unable to produce results in the form of generalizable principles that can be applied to particular cases. In fact, this has not been our primary problem... Our problem arises rather from the fact that our research challenges what others want to believe; our problem lies in obtaining an audience that will listen when the information is not palatable (1985:193)... "what we have is uncomfortable knowledge, the kind of knowledge that challenges established clichés and puts in question accepted solutions, and so those who champion them" (Coulson, cited in Stein, 1988:195).

The extent to which a scenario causes discomfort -without of course being rejected outright- will help it as a reframing device, and be of actual cognitive help contributing to the utility of the process. Wilkinson and Ramírez (2010) explored scenarios as conceptual reframing, Ramirez et al (forthcoming) explored how scenarios in so doing redirect managerial attention; in helping their users to 'think the unthinkable' (Kahn, 1962), discomfort would appear to be a useful criterion.

A second criterion to that of discomfort would be user ignorance or inattention (Ramírez and Ravetz, 2011). These would help the intended user to attend to that which has not been explored or understood well, with the scenarios highlighting which aspects they might want to invest research and educational resources into better engage.

If discomfort and ignorance, and not imagined future impact and present perceived uncertainty, were to be criteria with which to select drivers that most need to be considered in building scenarios, one would go beyond the unhelpful aspects of the plausibility/probability debate that has for so long, and in such an 
insidious way, crept into our understanding of scenario choices. Of course, practitioners using these criteria would need to carefully check that the scenarios that emerge are of actual help to the specific users and adhere to the agreed purpose of the intervention. This would re-position plausibility not as a condition of a future, nor as a quality of each scenario or the scenario set, but as a quality criterion of a co-produced conversation (Wilkinson and Ramírez, 2010) that scenarios orchestrate. The first author has tried this with a group of mining executives, re-positioning factors from an impact/uncertainty map into one of discomfort/ignorance, resulting in a very different set of high priority items for their top management to reconsider.

\section{CONCLUSIONS}

In this paper we have surveyed the history of the concepts of probability and plausibility, the problems of distinguishing them, the cultural stances that prefer the one over the other - often equating them with methodological preferences - and the difficulties that each approach encounters in practice. We have also suggested that it so far has been impossible to empirically settle how helpful the distinctions might be. We pinpointed how the tensions raised by plausibilitic and probabilistic approaches play out differently in five specific phases of scenario planning.

In our critique of the plausibility/probability debate we have also noticed that this distinction is but one divide amidst at least three culture clashes and orientations towards the future tied closely, if not fundamentally, with epistemological preferences and ontological worldviews. A given school of scenario planning may have oriented its preference in one fashion or another, but there is nothing deterministic about the choices schools have so far made - nor are they the only ones logically available, as the cube in figure seven illustrates. Alternative combinations may offer equally or even more fruitful approaches. For instance, scenarios that mesh science and plausibility would lead from lab experiments underway to consider logical outcomes (c.f. Moss et al, 2010). Scenarios that worked to approach probable scenarios in a qualitative fashion might limit and enumerate the likelihood of a discrete set of scenarios while employing rich ethnographic study to shed light on those probable scenarios. One could also design scenarios that take art seriously whilst from a quantitative approach, with some of the work in data visualization and other infographics for beautifully representing complexity as starting points, perhaps building on Tufte's (2001) insights. To summarize - beyond and between the plausibility/probability divide there are other possible attribute configurations -only some of which are depicted in figure seven - for rendering scenario sets productive in compelling, relevant and effective ways.

- Figure seven about here - 
We have surveyed how studies in social psychology shed light on some tendencies to resist living with openendedness and uncertainty, and instead lead us to seek closure prematurely and unhelpfully. Nevertheless, we have shown that despite the real difficulties offered by the plausibility - probability distinctions, the quest to distinguish them has persisted as an important characterisation of the field of scenario work. Our analysis leads us to suggest that many forms of the distinctions involved, at least as they have too often been invoked, are no longer helpful or productive. We have suggested alternative criteria- discomfort and ignorance- that might be more helpful in engaging with the contemporary forms of uncertainty that scenarios work with.

While assigning a numerical likelihood for a scenario can be seductive and can ease anxiety, what any form of scenario work seeks is to enhance prospective sense-making. An uncomfortable pause, staying with ambiguity and delving into ignorance may be of more value than a decisive judgement in this regard.

Our analysis leads us to call for careful caution when invoking the merits and perils of plausibility and probability; for greater reflexivity, for recognizing that 'not everything that counts can be counted' and not everything that is intuitive counts. We suggest that challenging the obscurity in the debates and clashes over plausibility and probability in scenario planning; noticing the attachments of one's own mindset and the commitments it can imply; opens up the possibility of enhanced, richer, and more productive prospective sense-making. 


\section{REFERENCES}

Ackoff, R. (1981) The Art and Science of Mess Management. Interfaces February 1981 vol. 11 no. 1 20-26

Adam, B. and Groves C. (2007), Future Matters: Action, Knowledge, Ethics, Brill. Leiden.

Amado, G. and Ambrose, A. (2001), The Transitional Approach to Change, Karnak Books, London.

Bosch, R. (2010), “Objectivity and Plausibility in the Study of Organizations”, Journal of Management Inquiry, Vol. 19 No. 4, pp. 383-391.

Bradfield, R., Wright, G., Burt, G., Cairns, G., and van der Heijden, K. (2005), "The Origins and Evolution of Scenario Techniques in Long Range Business Planning", Futures, Vol. 37 No. 8, pp. 795-812.

Cao, H.H., Han, B., Zhang, H. and Hirshleifer, D.A. (2011), “Fear of the Unknown: Familiarity and Economic Decisions", Review of Finance, Vol. 15, pp. 173-206.

Chermack, T.J. and van der Merwe, L. (2003), "The Role of Constructivist Learning in Scenario Planning", Futures, Vol. 35 No. 5, pp. 445-460.

Choo, C.W. and Bontis, N. (2002), The Strategic Management of Intellectual Capital and Organizational Knowledge, Oxford University Press, New York.

Cohen, S. (2001), States of Denial: Knowing about Atrocities and Suffering, Polit Press, London.

Consortium for Science, Policy and Outcomes (2009), "The Plausibility Project", available at http://www.cspo.org/projects/plausibility/ (accessed 19 May, 2012).

Davidson, P. (1982), “Rational Expectations: A Fallacious Foundation for Studying Crucial Decision-Making Processes", Journal of Post Keynesian Economics, Vol. 5 No. 2, pp. 182-198.

de Geus, A. (1988), "Planning as learning”, Harvard Business Review, Vol. 66 No. 2, pp. 70-74.

de Jouvenel, B. (1967), The Art of Conjecture, Basic Books, New York.

Denis J.L., Langley, A and Rouleay, D. (2006), "The Power of Numbers in Strategizing", Strategic Organization, Vol. 4 No. 4, pp. 349-377.

Dye R, Sibony O and Vigier, P. (2009), “Strategic Planning: Three Tips for 2009”, McKinsey Quarterly, April, pp. 1-3.

Emery, F. (1977), Futures We Are In, Martinus Nijhoff, Leiden.

Foucualt, M. (1972). Power/Knowledge. Pantheon Books. NY.

Fox Keller, E. (2002) Making Sense of Life: Explaining Biological Development with Models, Metaphors, and Machines, Harvard University Press, Cambridge, MA.

Freud, S. (1920) A General Introduction to Psychoanalysis; Trans. by G. Stanley Hall. New York: Boni and Liveright; Bartleby.com, 2010.

Funtowicz, S. and Ravetz, J. (1993), “Science for the Post-Normal Age”, Futures, Vol. 25 No. 7, pp. 735-755.

Gardner, D. (2010), Future Babble: Why Expert Predictions Fail-and Why We Believe Them Anyway, 
McClelland and Stewart, Toronto.

Gershon. M. (1999) The Second Brain, Harper Collins, New York.

Gioia, D.A., and Mehra, A. (1996), "Review of Karl E. Weick's Sensemaking in Organizations", Academy of Management Review, Vol. 21, pp. 1226-1230.

Glenn J.G. and the Futures Group International (2009) "Scenarios". Chapter 19 in J.G. Glenn and T.J. Gordon (Eds), Futures Research Methodology version 3.0, The Millennium Project, Washington, D.C and current in Global Futures Intelligence System www.themp.org.

Godet, M. (2000), "The Art of Scenarios and Strategic Planning: Tools and Pitfalls", Technological Forecasting and Social Change, Vol. 65, pp. 3-22.

Haeckel, S.H. (2004), "Peripheral Vision: Sensing and acting on Weak Signals Making Meaning Out of Apparent Noise: the Need for a New Managerial Framework", Long Range Planning, Vol. 37 No. 2, pp. 181-189.

Hatchuel A., Le Masson, P. and Weil, B. (2004), "C-K Theory in Practice: Lessons from Industrial Applications", in Proceedings of the 8th International Design Conference, Dubrovnik, $18^{\text {th }}-21^{\text {st }}$ May, 2004.

Heath, C., and Tversky, A. (1991), "Preference and belief: Ambiguity and competence in choice under uncertainty", Journal of Risk and Uncertainty, Vol. 4, pp. 5-28.

Inayatullah, S. (2002), "Pedagogy, Culture and Future Studies”, in Dator, J.A. (Ed.), Advancing futures: Futures Studies in Higher Education. Westport, CT: Praeger, pp. 109-124.

Kahn, H. (1962), On Thermonuclear War, Princeton University Press, Princeton, N.J.

Kahneman D. and Klein G. (2009), "Conditions for Intuitive Expertise: A Failure to Disagree”, American Psychologist, Vol. 64 No. 6, pp. 515-526.

Klein, G. (2002), Intuition at Work: Why Developing Your Gut Instincts Will Make You Better at What You Do, Currency Doubleday, New York.

Klein, G. (2004), The Power of Intuition: How to Use Your Gut Feelings to Make Better Decisions at Work, Currency Doubleday, New York.

Knight, F.H. (1921) Risk, Uncertainty, and Profit. Boston, MA: Hart, Schaffner \& Marx; Houghton Mifflin Company

Lang, T. (2012) Essays on How Scenario Planning and the Building of New Social Capital Are Related. Unpublished DPhil Dissertation, University of Oxford

Locke, J.: (1690) An Essay Concerning Human Understanding: Book 4: Chapter 6

Loewenstein, G., Weber, E.U., Hsee, C.K. and Welch, E. (2001), "Risk as feelings", Psychological Bulletin, Vol. 127, pp. 267-286.

Maturana H. and Varela F. (1980), Autopoiesis and Cognition, Reidel Publishing Co., Dordrecht, Holland.

Meckler, M. and Baillie, J. (2003), "The truth about social construction in administrative science", Journal of Management Inquiry Vol. 12, pp. 273-284.

McMaster, M. (1996), "A View From the Emerging Science of Complexity", available at http://www.community-intelligence.com/?q=node/140 (accessed 15 June, 2012). 
Menzies Lyth, I. (1960), "Social Systems as a Defense Against Anxiety: An Empirical Study of the Nursing Service of a General Hospital", Human Relations, Vol. 13, pp. 95-121.

Millett, S.M. (2003), "The Future of Scenarios: Challenges and Opportunities", Strategy and Leadership, Vol. 31 No. 2, pp. 16-24.

Millett, S.M. (2009), "Should Probabilities Be Used With Scenarios?”, Journal of Futures Studies, Vol. 13 No. 4 , pp. 61-68.

Moss, R. H., J. A. Edmonds, K.A. Hibbard, M.R. Manning, S.K. Rose, D.P. van Vuuren, T.R. Carter, S. Emori, M. Kainuma, T. Kram, G.A. Meehl, J.F.B. Mitchell, N. Nakicenovic, K. Riahi, S.J. Smith, R.J. Stouffer, A.M. Thomson, J.P. Weyant and T. J. Wilbanks. (2010). "The Next Generation of Scenarios for Climate Change Research and Assessment". Nature, 463: 747-756.

Myers D.G. (2002), Intuition: Its Powers and Perils, Yale University Press, New Haven, CT.

Normann, R. (2001), Reframing Business: When the Map Changes the Landscape, John Wiley and Sons, Chichester.

Oxford English Dictionary (2012) “Plausible Deniability”, available at http://www.oed.com/view/Entry/145466 (accessed 14 August 2012).

Oxford Futures Forum (2008), Oxford Futures Forum, available at http://www.sbs.ox.ac.uk/newsandevents/conferences/oxfordfuturesforum/Pages/default.aspx (accessed 19 May, 2012).

Perrow, C. (1984) Normal Accidents: Living with High-Risk Technologies, Basic Books, NY,

Postma, T. and Libel, F. (2005), "How to Improve Scenario Analysis as a Strategic Management Tool?", Technological Forecasting and Social Change, Vol. 72 No. 2, pp. 161-173.

Ramírez, R., Selsky, J. and van der Heijden, K. (2010), Business Planning in Turbulent Times, Earthscan, London.

Ramírez, R. and Ravetz, J. (2011), "Feral futures: Zen and Aesthetics", Futures, Vol. 43, pp. 478-487.

Ramirez, R., Osterman, R. \& Gronquist, D. (forthcoming) “Linking Scenarios and Early Warnings to Focus Managerial Attention on Possible Futures" accepted for publication Technological Forecasting and Social Change

Ringland, G. (1998), Scenario Planning: Managing for the Future, John Wiley and Sons, Chichester.

Rosenthal, R. (1966), Experimenter Effects in Behavioral Research, Appleton-Century- Crofts, East Norwalk, CT.

Roxburgh, C. (2009), “The Use and Abuse of Scenarios”, McKinsey Quarterly, November, pp. 1-10.

Sarewitz, D., Pielke, R.A. and Byerly Jr., R. (2000), Prediction: Science, Decision Making and the Future of Nature, Island Press, Washington, D.C.

Schoemaker, P.J.H. (1993), "Multiple Scenario Development: Its Conceptual and Behavioral Foundation”, Strategic Management Journal, Vol. 14 No. 3, pp. 193-21.

Schoemaker, P.J.H., Day. G.S. and Snyder S.A. (2013), “Integrating organizational networks, weak signals. strategic radars, and scenario planning", Technological Forecasting \& social Change, Vol. 80, pp. 815-824.

Schwartz, P. (1991), The Art of the Long View - Planning for the Future in an Uncertain World, (Revised 1996), John Wiley and Sons, Ltd, Chichester. 
Selin, C. (2003), "The Art and Science of Scenario Planning", Research Management Processes under Rapid Change. The Danish Institute for Studies in Research and Research Policy Research Paper 2003/9, Aarhus, Denmark, pp. 126-134.

Selin, C. (2006), "Trust and the Illusive Force of Scenarios", Futures, Vol. 38 No. 1, pp. 1-14.

Selye, H. (1974), Stress Without Distress, Penguin Books, Chichester.

Senge, P. (2006), The Fifth Discipline, revised edn. Currency, New York.

Star, S.L., and Griesemer, J.R. (1989), "Institutional Ecology, "Transactions" and Boundary Objects: Amateurs and Professionals in Berkley's Museum of Vertebrate Zoology, 1907-39", The Social Studies of Science, Vol. 19, pp. 387-420.

Starbuck, W.H. and Mezias, J.M. (1996), “Opening Pandora's box: studying the accuracy of mangers' perception", Journal of Organizational Behaviour, Vol. 17 No. 2, pp. 99-117.

Stein, H. (1988), "Uncomfortable Knowledge: An Ethnographic Clinical Training Model”, Family Systems Medicine, Vol 6 No. 1, pp. 117-128.

Tufte, E. (2001). Envisioning Information. Cheshire, CT: Graphics Press

UK Government Office for Science (2009)

http://www.sciencedirect.com/science/article/pii/S0016328712001437

van der Heijden, K. (1996), Scenarios: The Art of Strategic Conversation. (Revised 2005), John Wiley and Sons, Chichester.

van der Heijden, K. (2008), Turbulence in the Indian agriculture sector: A scenario analysis, in Ramírez, R., Selsky, J. and. van der Heijden, K. (Eds.), Business Planning for Turbulent Times, (Revised 2010), Earthscan, London, pp. 87-102.

van der Leeuw, S., Costanza, R., Aulenbach, S., Brewer, S., Burek, M., Cornell, S., Crumley, C., Dearing, J.A., Downy, C., Graumlich, L.J., Heckbert, S., Hegmon, M., Hibbard, K., Jackson, S.T., Kubiszewski, I., Sinclair, P., Sörlin, S. and Steffen W. (2011), "Toward an Integrated History to Guide the Future", Ecology and Society Vol. 16 No. 4 , p. 2.

Vennix, J. (1996). Group Model Building: Facilitating Team Learning Using System Dynamics. Chichster: john Wiley \& Sons.

Wack, P. (1984), "Scenarios: The Gentle Art of Re-perceiving: A Thing or Two Learned While Developing Planning Scenarios for Royal Dutch/Shell”, Unpublished Working Paper, Harvard Business School, Boston, pp. 1-77.

Weick, K.E. (1993), "The Collapse of Sensemaking in Organizations: The Mann Gulch Disaster", Administrative Science Quarterly, Vol. 38 No. 4, pp. 628-652.

Weick, K.E. (2001), Making Sense of the Organization, Blackwell Publishers, Maiden, MA.

Wilkinson, A. (2007). "Scenarios: Texts and Contexts.", Paper presented at Global Environmental Futures: Interrogating the Practice and Politics of Scenarios, Watson Institute for International Studies, Brown University, 23-24 March, 2007.

Wilkinson, A. (2009) "Scenarios Practices: In Search of Theory", Journal of Futures Studies, Vol. 13 No. 3, pp. 107-114. 
Wilkinson A. and Ramírez R. (2010) "Canaries in the Mind: Exploring How the Financial Crisis Impacts 21st Century Future-Mindfulness", Journal of Futures Studies, Vol. 14 No. 3, pp. 45-60.

Wilkinson, A. and Eidinow, E. (2008), "Evolving practices in environmental scenarios: a new scenario typology", Environmental Research Letters, Vol. 3 No. 4, pp. 1-11.

Wilson, I. (2000), "From Scenario Thinking to Strategic Action", Technological Forecasting and Social Change, Vol. 65 No. 1, pp. 23-29.

Wright, A.D. (2005), "The Role of Scenarios as Prospective Sensemaking Devices", Management Decision, Vol. 43 No. 1 , pp. 86-101.

Wright, G. and Goodwin, P. (2009) “Decision making and planning under low levels of predictability: enhancing the scenario method", International Journal of Forecasting Vol. 25 No. 4, pp. 813-825. 


\section{$14^{\text {th }}, 15^{\text {th }}, 16^{\text {th }}$ centuries}

\section{Plausibility}

(only as of 1541 in English)

1.a Acceptable, agreeable, pleasing, gratifying, winning

public approval, popular.

1.b 1577-8 Of a person (and manners): affable, pleasant, winning, ingratiating.

21542 Expressing applause or approbation, plausive, applausive

41565 Seeming reasonable, probable, or truthful; convincing, believable

4a Seemingly probable argument, but formerly also having a false appearance of veracity
Probability

Classical Latin = "that may be proved, demonstrable, acceptable, plausible credible, worthy of approval, having appearance of truth, likely, indicating probability"

late 14th

(French), 1387 (English)

1.a. 1387 That commends itself to mind; worthy of acceptance or belief (in negative $=$ specious or plausible)

2.a 1596 Having the appearance of truth; that may in view of present evidence be reasonably expected to happen or be the case; likely. 


\section{$7^{\text {th }}$ centuries}

\section{Plausibility}

4a. Deception a person (and manners): affable, pleasant, winning, ingratiating.

1658 Hobbes: Leviathan III. xLii. 303 "All such as had both the ambition to attempt the attaining of the Kingdome, and the art to deceive the People, by counterfeit miracles, by hypocriticall life, or by orations and doctrine plausible"

\section{Probability}

\section{Begins to take on \\ 'scientific' colour}

1654 Pascal-Fermat

correspondence

1657 Huyguens - first

'scientific' approach

1657 Locke: Ess. Humane

Understanding IV. Vi. 297

"Possibly inquisitive and observing Men may, by strength of Judgement, penetrate farther, and on Probabilities taken from wary Observation, often guess right at what Experience has not yet discovered to them"

figure 2 


\section{$18^{\text {th }}, 19^{\text {th }}, 20^{\text {th }}$ centuries}

\section{Plausibility \\ Probability}

Building on Milton (1649), these centuries saw plausibility as depicting

3.a. The quality of an argument

(or statement) of seeming

reasonable or probable, appearance of believabilty and credibility,

3.b. but frequently with the implication of speciousness, extening to

3.c. the capacity of a person to sound plausible; persuasiveness; (decepetive) convincigness

Leading to 'plausible deniability' as a form of lying by a State (Wise, Washingtan Post 14/8/1978 A2/3)
Bernouli (1713), Bayes (1736) and Laplace (1774) lead on the development of the mathematics of probability, followed by further work by Gauss (1823). Markov (1906), Kolmogorov (1931) and many others.

\section{figure 3}




\section{Different Epistemologies}

\section{Bifurcation of the scenario community}

\section{Futurology Futurizing}

Better prediction Keep an open mind

Assign probabilities Appreciate multiple perspectives

Uncertainty due to limited knowledge Intrinsic uncertainty

Environment as independent of client Environment as casual and client specific

Scenarios as foreground Relationship of actor-scenarios

as foreground 


\section{The history of business scenarios}

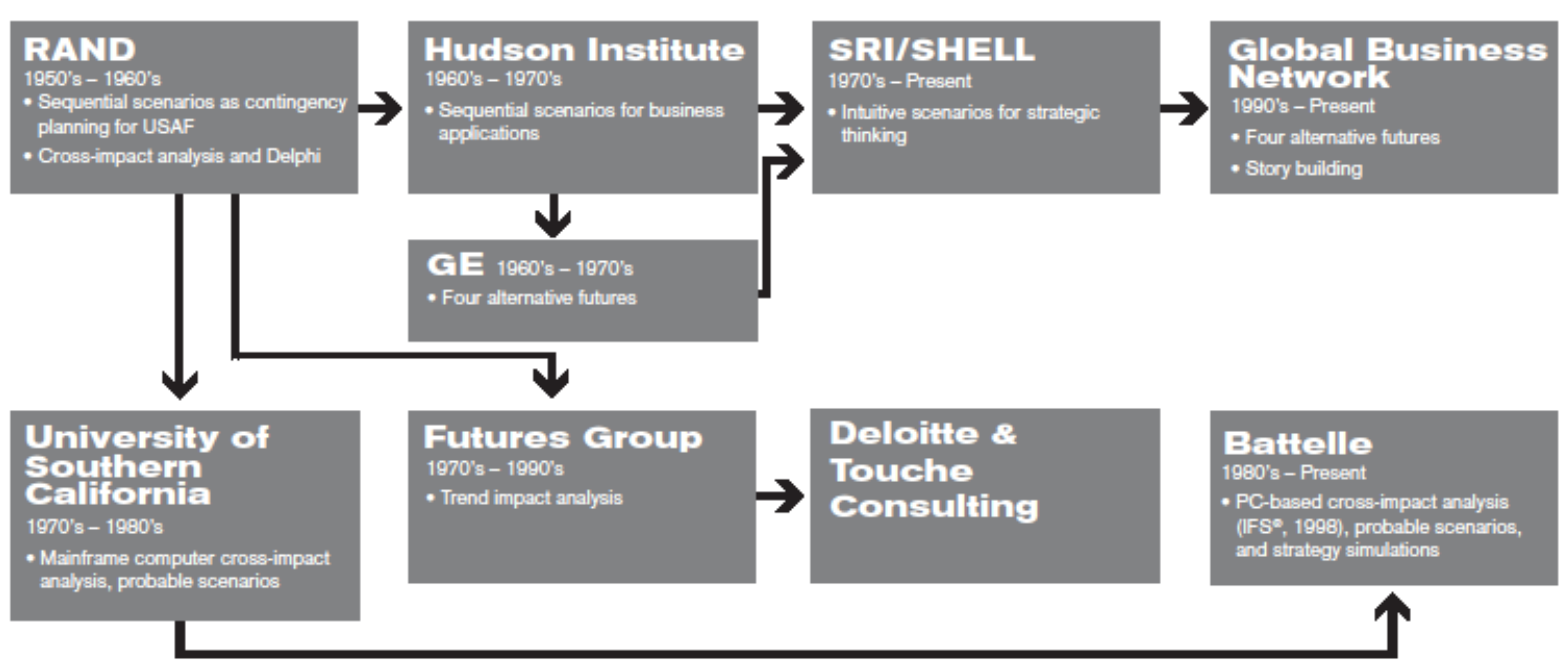

figure 5 


\section{Learning from the Future}

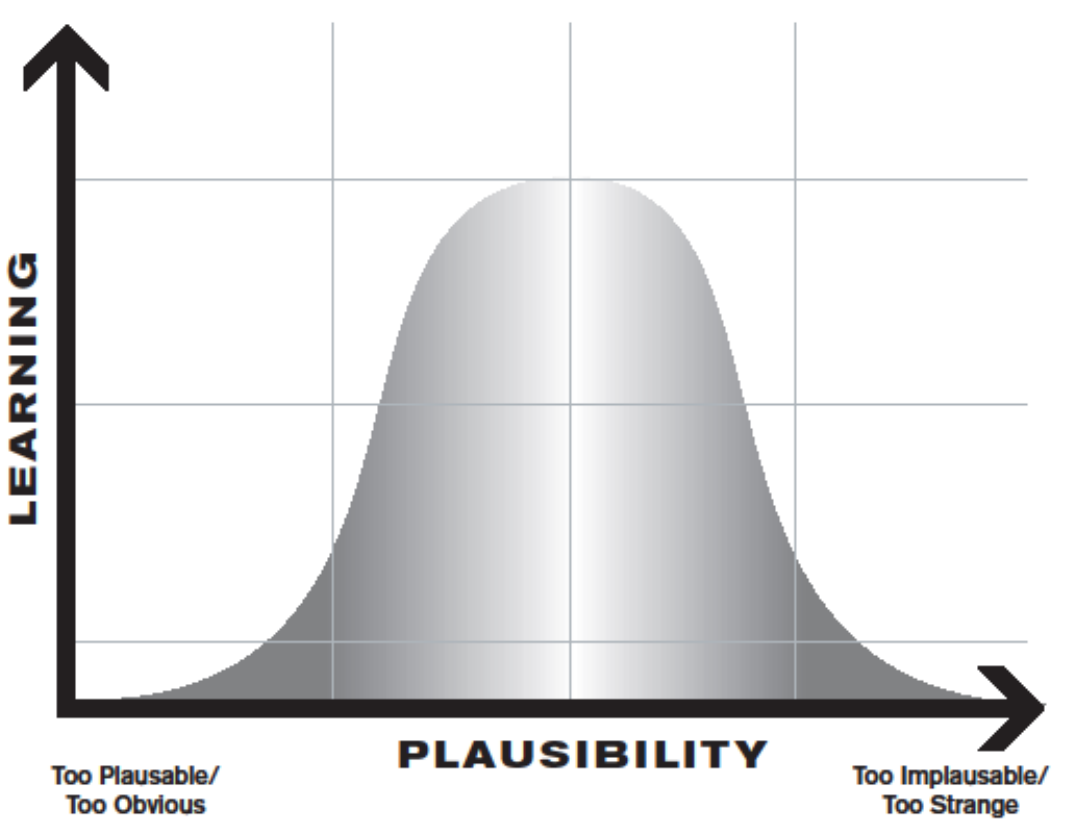




\section{Alternative}

scenario configurations

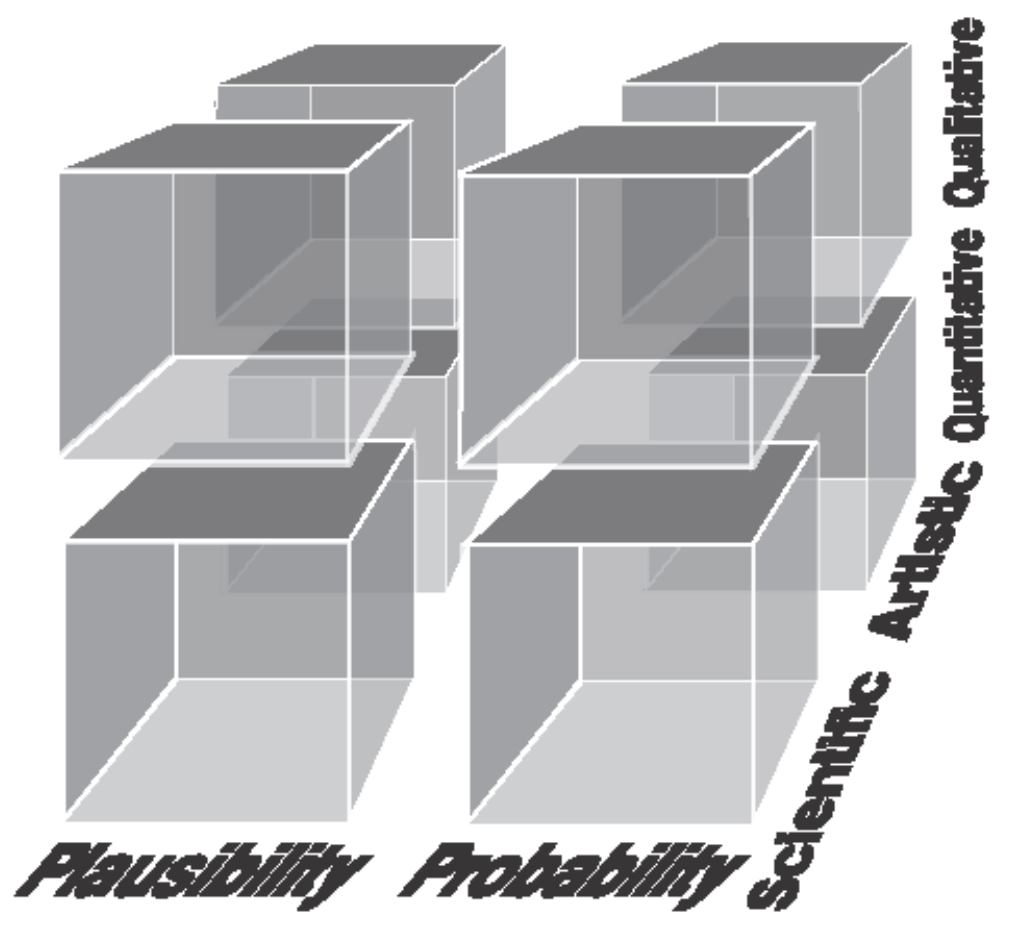

figure 7 


\section{Millett's Analysis of Plausibility and Probability}

\section{Plausibility \\ Plausibility as specious: 3rd period \\ Probability \\ Probability as likely: \\ 1st period \\ Plausibility as intuitive: 1st period \\ Bayesian judgement: 3rd period \\ Probability for precise judgment, peer review: 2nd \& 3rd periods \\ Bayesian probabilities: 3rd period \\ Probability as likely: 1st period \\ Plausibility as intuitive: 1 st period \\ Cross-impact analysis: 3rd period \\ Probability as best guesses: 1 st period \\ Quantitative exercise: 3rd period}




\section{Appendix}

\section{Micro-analysis of Millet's contrast of probability and plausibility}

As we saw above, a crucial and up to now ignored difficulty to establish the distinct merits of probability and of plausibility in scenario planning work arises from the confused way in which the very definitions of 'plausibility' and 'probability' that relate and distinguish them have evolved over time. To surface how tricky the terms and their connotations are when used by a well meaning and intellectually rigorous reflective practitioner, we revisit the argument Millett (2009:66-7) made for using probability rather than plausibility in conjunction with scenarios. In our comparison, we reproduce his original text in italics, but here with key terms underlined), and we have dated the definitions he used in each of the three periods we proposed above (in bold parentheses within Millett's original text):

"the advantages for using probabilities with scenarios include:

- $\quad$ Although all scenarios should be treated equally, the reality is that they typically are not. Both scenario generating teams and executives gravitate toward the scenarios that they find to be "most interesting, "which typically reflect corporate cultural biases and wishful thinking. (third periodplausibility as specious)

The use of probabilities actually forces scenario teams and executives to examine likely scenarios (first period, having the appearance of truth) that they might otherwise dismiss as plausible but not attractive.

- $\quad$ The use of Bayesian probabilities encourages people to explain their judgments (third period, rigorous judgement), thereby exposing hidden assumptions, biases, and expectations that too often go unarticulated in the generation of purely intuitive scenarios (first period - acceptable, agreeable, pleasing, gratifying, winning public approval, popular)

- $\quad$ Probabilities demand more precision and explanation of underlying mental models behind the scenario stories. All scenarios are to one extent or another exercises in expert judgment; the use of probabilities drives people toward making those judgments explicit and subject to peer review and criticism. (second and third periods, where probability = scientific) ${ }^{4}$.

- $\quad$ The array of scenarios according to their a posteriori probabilities of occurrence provides a map of both likely and desirable futures. There may be a distinct difference between the most likely (futuring) and the most desirable (visioning) scenarios. Analytical scenarios based on modelling, cross-impact analysis, and Bayesian probabilities (third period, scientific) allow teams and executives to better understand the conditionality of any scenario and determine what would have to happen to improve the probability that the most desirable scenario could be made to happen. In other words, the use of probabilities facilitates strategy development by examining different conditions and their likely outcomes (first period, appearance of likelihood) given different resource commitments (Millett, 2003).

- Models using cross-impact analysis and probabilities (third period, scientific) provide a tool for simulations of potential disruptive events and corporate strategies. Such simulations are very difficult if not impossible to perform with strictly intuitive scenarios (first period). In addition, a systems approach with modelling and simulation is consistent with the tenants of Peter Senge's The Fifth Discipline (Senge, 2006).

- $\quad$ Probabilities are best quesses based on trend analysis, intuition, and expectations for the future that can be readily changed as new information becomes available or events occur (first period - likelihood). The tracking of probabilities goes hand in hand with the tracking of trends and provides a framework for continuously revising scenarios.

- $\quad$ The use of probabilities with scenarios facilitates their being used as different starting points for econometric and statistical forecasts. It also provides the basis for running different kinds of quantitative exercises, such as real options analysis. (third period - quantification). 
The above suggests that Millett's analysis suffers from the confused etymology of plausibility and probability. His connotations from different periods are arguably inevitable if one expresses one's thinking in English. The confusions weaken the argumentation. Figure 8 summarises the positions used in the extracts analyzed above.

\section{- $\quad$ Figure 8 about here -}

Millett's proposed comparisons are particularly hampered by the $17^{\text {th }}$ century confusions. Millett only used the negative definition of plausibility that began as one of many possible definitions in the $1^{\text {st }}$ period and became solidified in the $3^{\text {rd }}$ one - he does not attend to the positive aspects of the definition, and he ignores the negative aspects of probability. 


\section{ENDNOTES}

\footnotetext{
${ }^{1}$ The second Oxford Futures Forum (www.oxfordfuturesforum.org.uk ) that explored theories of sense-making in scenario work held in 2008 included a session on plausibility based on the expressed interest of a number of practitioners and scholars. Drawing on these discussions as well as applied work at the Center for Nanotechnology in Society (CNS-ASU), [name removed for blind review purposes] hosted, in 2009, an international interdisciplinary workshop exploring the conceptual and methodological dimensions of foresight. The later 'Plausibility Project' continued in 2012 with a joint meeting focused on innovation, ethics and plausibility sponsored by the EC's Joint Research Centre.

${ }^{2}$ This would suggest that there are possible 'normal accidents' (Perrow 1984) built into the use of any language. That is partly because language can be understood not neutral or objective; but as shaping understanding, and reflecting and articulating power (Foucault, 1972).

${ }^{3}$ While there are other notable histories of business scenarios (Bradfield et al 2005; Wilkinson \& Eidinow 2008), we stay with Millet's interpretation.

${ }^{4}$ There is no empirical evidence that expert judgement is better at determining the future than non-expert judgment (c.f. Gardner, 2010). But that aspect of Millet's reasoning is not the centre of this article's argument. Also, peer review and criticism is possible without probability, as any art critic knows.
}

\section{Rafael Ramírez}

Dr Rafael Ramírez holds a doctorate from the Wharton School and has worked with scenarios and futures since 1980. He was Visiting Professor of Scenarios and Corporate Strategy at Shell International from 2000 to 2003 , and from 2008 to 2010 Chairman of the World Economic Forum's Global Agenda Council on Strategic Foresight. He directs the Oxford Scenarios Programme and is also Senior Research Fellow Futures at the Oxford Martin School. Rafael has worked as a consultant and management educator in over 25 countries. He has published 6 books and scholarly papers in Futures, Harvard Business Review, Long Range Planning, Organization, Organizational Aesthetics, Organization Studies, and the Strategic Management Journal.

\section{Cynthia Selin}

Dr. Cynthia Selin is an Assistant Professor at the School of Sustainability and the Consortium for Science, Policy and Outcomes at Arizona State University engaged in research about the social implications of emerging technologies. She works primarily with the Center for Nanotechnology in Society where she is responsible for the research program on Deliberation and Anticipation and directs the Center's outreach activities. Dr. Selin teaching at ASU's School of Sustainability and research with the Center for Nanotechnology in Society is focused on anticipatory governance and future-oriented methods. In 2000 she completed a M. A. in Science, Technology and Society and earned her doctorate from the Copenhagen Business School's Institute for Management, Politics and Philosophy in 2006. Dr. Selin has published in Science, Technology and Human Values, Futures, and Time \& Society. 